\title{
Public Health Funding and Health Service Delivery-A Case Study of the Gauteng Province, South Africa
}

\author{
Rudzani E Rasivhetshele \\ Regenesys Business School. Johannesburg, South Africa \\ Prof Krishna K Govender \\ Regenesys Business School. Johannesburg, South Africa \\ krshnag@regenesys.co.za
}

\begin{abstract}
In South Africa, the provision of health care services by public institutions has been reported to be under tremendous funding constraints. This paper reports the findings of an exploratory study to determine the funding process as well as factors which influence funding of the public health sector in Gauteng South Africa by interviewing relevant officials in the province, as well as outpatients at certain public hospitals, since the funding will eventually impact the level of health-care service delivered. It became evident that allocating funds to the Gauteng Department of Health $(\mathrm{GDoH})$ with specific conditions attached thereto, is an acceptable way of funding national policies and ensuring that such funds are 'protected' and spent only for the purposes as stipulated in the accompanying grant framework. There is need for the GDoH and the Gauteng Provincial Treasury (GPT) to ensure that the well-established provincial budgeting processes are followed, which should be accompanied by building technical capacity to ensure that all areas of spending are well funded, information is communicated to all the public health institutions, and that every unit adheres to the budget limitations to avoid overspending.
\end{abstract}

Keywords: public health service; health service financing; budgeting

\section{ACRONYMS}

CFO: Chief Financial Officer, DORA: Division of Revenue Act, EXCO: Executive Council, GDoH: Gauteng Department of Health, GPT: Gauteng Provincial Treasury, MDG: Millennium Development Goals, MTEF: Medium-Term Expenditure Framework, MFMA:Municipal Finance Management Act, NDoH: National Department of Health, PFMA: Public Finance Management Act, WHO: World Health Organisation

\section{INTRODUCTION}

In recent years, government funding for public health service institutions in South Africa has not been increasing proportionate to the increase in the demand for health services. This is primarily in the Gauteng province, where in 2010, it was declared the most populous province in the country, since the total population grew from of 7.8 million in 1996 to 12.3 million people in 2011 (Statistics South Africa, 2012). In recent past financial years, the tertiary hospitals in the Gauteng province have always been spending more than the budget allocated, citing underfunding from the province as the main reason (Section 27, 2013). From the publics' perspective, the lack of adequate funding is evident through continuous reports of poor service delivery, dilapidated and or inadequate infrastructure, exorbitant provision of 
medical supplies and a number of failures within the health system (Section 27, 2013). There are various reasons that may be contributing to the above state of affairs, of which the level of funding may be the most important.

Stephen, Muirhead, Doherty and Muheki (2000:127-147) revealed that an expanding public health sector budget accompanied by foreseeable sources of funding, is an important basis for improving public health service delivery. The aforementioned researchers argued that the budgeting process in South Africa has limited or constrained the drive towards achieving adequate funding in many ways. It is therefore possible that the provincial resource allocation process does not necessarily demonstrate efforts to attain sufficient funding for the provincial health sector.

In view of the above, this research was conducted to broadly understand the budgeting process, and determine the key factors that drive the funding of public health service institutions and the provincial resource allocation policy foundations that should be considered when resourcing the Gauteng public health sector. More specifically, this study was undertaken to identify factors that the Gauteng Department of Health (GDoH) and the Gauteng Provincial Treasury (GPT) should consider to ensure that the allocation of budgets to the public health institutions is improved.

\section{LITERATURE REVIEW}

As the primary custodian of policy development for the public health system, the National Department of Health (NDoH) indicated in its 2012/13 Annual Performance Plan that it will continue to implement a number of interventions to holistically address the health needs of all South Africans. These interventions are guided by the South African government's commitment to achieve a 'long and healthy life for all South Africans' (National Department of Health, 2012). However, health interventions have in the main, been targeted towards addressing clinical issues within public health institutions, and less attention is continually being paid towards sorting out issues of allocation efficiencies and improving the level of funding.

In the case of Gauteng, the 2012 Medium Term Expenditure Framework (MTEF) of the Gauteng Department of Health (GDoH) , the 'balanced budget' was identified as one of the key elements of the fifth strategic objective, which was referred to as 'organisation excellence'. There are many inputs that should play a role to ensure that jointly, they contribute to the attainment a balanced budget, of which, resource allocation forms the basis that all factors should align with. According to the World Health Organization (WHO) the purpose of health financing is to make funding available, as well as to set the right financial incentives to providers, to ensure that all individuals have access to effective public health and personal health care (WHO, 2000). Although it is reported in the WHO's 2010 Annual Report that all countries, rich and poor, face challenges in assuring, then sustaining universal coverage and all must address the core issues of health financing (WHO, 2010). The challenge in most countries is that demands and expectations frequently outstrip a country's capacity to provide services, and there is also evidence of inefficiency in the way resources are used, partly because health governance systems are often unable to keep pace with the expansion of the health sector. This seems to be the case in South Africa, where the state health institutions are not funded to a level that will enable them to meet the demand and expected healthcare services. 
In $1994^{1}$, the public health system in South Africa was reformed administratively along the lines of the new Constitution. Nine provincial health administrations were created and made responsible for the delivery of both hospital and primary health care. The provincial administrations transfer a portion of their budgets to local authorities who also render primary health care services. Furthermore, since 1994, a number of significant changes have occurred in the financial arrangements of the South African Government in general, with major implications for the rendering of health services to the public. These included inter-alia, the introduction of a fiscal federal system affecting the financing and budgeting of virtually all significant social services, including health, social development and education. A key issue being the role and extent of provincial discretion relative to national policy requirements, and whether a proper balance is currently maintained.

In the 1997/98 financial year the public sector officially switched over to a fiscal federal system whereby budgets for provincial public health systems were determined by provincial legislatures, with less dictation by national policy. The funds made available to the provinces were allocated through an unconditional (equitable share) grant allocated from the national budget. The equitable share allocation to provinces was all not earmarked for health services, but it was the prerogative of the provinces to determine the share of the resources to be allocated towards public health. Due to competing provincial priorities between social, economic, and governance services, the realisation of adequate funding of health was a challenge, and provinces could not always allocate adequate resources required for delivering public health care at an optimal level (Thomas \& Gibson, 2004).

In April 1997, three years into South Africa's democratic dispensation, the National Department of Health published a White Paper on the transformation of the health system in South Africa (National Department of Health, 1997). However, Stephen et al., (2000) asserted that an admission was made that the funding of the public health care system in South Africa had reached a critical juncture and much was done post publication of the White Paper to improve equity in the funding of the public health care in the few years of the democratic government, the trend appeared to have been reversed, as there were tendencies of decreased funding of primary health care parallel to an increase in inequities within the public health sector funding system.

McIntyre (2007) reflected on the MTEF which was introduced as three year rolling budgets for all national and provincial departments, and that the move towards global provincial budgeting appears to have slowed the pace of relative redistribution of health budgets somewhat, and in some cases, most notably Gauteng, has reversed the redistribution process. Furthermore, the move to a fiscal federalism approach, in line with the South African Constitution, appeared to have shifted the equity and budget appropriateness focus to that of the total provincial budgets. The most important implication and unintended consequence of fiscal federalism was the fact that it actually resulted in the expansion of inequities for some provinces. Depending on competing provincial priorities and prevailing budget pressures, the provincial legislature had the discretion to determine how much should be allocated to each function. The budget allocation also depended on the capacity of each provincial department to motivate for funding. Those departments with capacity to motivate well got more funds while the others received less.

\footnotetext{
${ }^{1}$ South Africa became a democratic country after the first general elections in 1994.
} 
Within the provincial sphere of government, the compilation and preparation of a provincial budget is provided for by the applicable legislation, that is, the Public Finance Management Act (PFMA), Act No. 1 of 1999, as amended by Act No. 29 of 1999. This regime is also applicable to the Gauteng Department of Health, which is primarily responsible for the management of the public health sector in the province. At the end of the 2007/08 financial year, the Gauteng Department of Health spent R639 million over the allocated budget of R12 billion. The trend of spending more than the allocated budget continued to the end of the 2009/10 financial year. However, at the end of the 2010/11 financial year, the department spent less than the budget, by an amount of R279 million.

Given the above background to the study, the research was conducted exploratory to determine the funding process as well as factors which influence funding of the public health sector in Gauteng South Africa by interviewing relevant officials in the province, as well as outpatients at certain public hospitals, since the funding will eventually impact of the level of service delivered.

\section{RESEARCH METHODOLOGY}

Primarily a qualitative research approach was used, whereby the researchers identified key respondents people of the provincial budgeting process, and the National Treasury, NDoH, GPT and the GDoH, and held one-on-one interviews with these identified individuals using a questionnaire $^{2}$. The questions did not only require information and opinions of respondents, but also afforded the interviewer the opportunity to probe the depth of the participants' understanding of the issues surround the study. In addition, to interviewing treasury officials, outpatients who visited specific public hospitals were also intercepted and questioned.

Although Gauteng is the smallest province in South Africa, it remains the province with the highest number of public health institutions (Stats SA, 2012). For the purpose of this research, judgment sampling was also used, in particular to select the outpatients at the identified hospitals. The sample comprised:

- The National Treasury - four senior managers who were in the Public Finance Unit and two senior managers form the Provincial Budget Analysis Unit. Only one, Dr Mark Blecher who was the Chief Director Finance agreed that his identity may be disclosed.

- The GPT - two managers who were in the Public Finance Unit and one manager in the Budget Management Unit, one of whom, Donald Onyango, Director: Public Finance in the Social Sector, agreed to have his identity disclosed.

- The GDoH-five managers from various units were selected, including Abbey Marokoane the Acting Chief Financial Officer, who also agreed to have his identity disclosed.

- Two hundred outpatients were also interviewed from four public hospitals in the Gauteng province.

\section{FINDINGS}

It became evident that health is a provincial priority, since reference was made to the speech of the Honourable Premier of Gauteng, who in her 2013 'State of the Province' address, conceded that when she took Office in 2009, the state of Gauteng's public health institutions was unsatisfactory. This was due to various reasons, including the outsourcing of management functions which resulted in poor management of human and financial resources. To address these, highly skilled personnel were brought-in, the leadership in the GDoH was re-established,

2 See Appendix A for the questionnaire 
and a comprehensive turnaround strategy was initiated. The team was mandated to focus on restoring effective controls and systems and improving efficiencies, capacity and management in key areas (Gauteng Office of The Premier, 2013).

From the feedback received from national and provincial government officials, it was apparent that health service provision is being prioritised, since all the senior management officials interviewed agreed that public health is both a national and provincial priority and the acceptance of public health as a priority has started to show in the manner in which public health services are being funded.

The Gauteng Provincial Treasury participant indicated that in 2103 the Provincial Treasury attempted to turn around the department by stabilising the finances of the health sector, and allocated an additional budget allocation of R1.1 billion to supplement funding for the nonnegotiable items that make the health institutions functional (Gauteng Treasury, 2013).

Both the Gauteng Provincial and the National Treasury participants argued that it is a legislated requirement that the health budgets are prepared according to an annual cycle, and formulated to contribute to high-quality and sustainable services. The Gauteng Department of Health does prepare its budgets within the MTEF and uses a top-down estimate of aggregate resources, determined at Head Office level, for institutional expenditure consistent with macro-economic stability, and bottom-up estimates of the cost of carrying out policies determined by public hospitals, both existing and new; and a framework that reconciles these costs with aggregate resources. The MTE is a rolling process repeated every year and aims at reducing the imbalance between what is affordable and what is demanded by line ministries. It is called "medium-term" because it provides data on a prospective basis, for the current budget year and for following years, showing estimates over three years.

During the engagements with the National Treasury's Provincial Budget Analysis, it was debated that that the National Treasury is mandated (as provided for in the Public Finance Management Act) to ensure that government in all spheres, plans and budgets within the prescripts of the MTEF. The National Treasury and the Gauteng Provincial Treasury participants stated that within the planning and budgeting processes, the health sector does take into account the MTEF by bringing together policy-making, planning, and budgeting early in the budgeting cycle, with adjustments taking place through policy changes.

The National and the Gauteng Treasury referenced a World Bank Report with regards to the implementation of the MTEF in Malawi, in supporting its arguments that the MTEF is a tested and effective tool that can address the funding gaps within the health sector. In Malawi, for example, since 1995 the four largest spending ministries (Agriculture, Education, Health, and Works) piloted implementation of the Medium-Term Expenditure Framework in preparation for their 1996-97 budgets. The pilot was confined to the recurrent budget and, within that, the non-wage and non-salary recurrent expenditure. The rationale for this was that the real test of the Government's priorities was to be found in spending in this latter category. It is worth noting, however that it has been based on the log frame approach, which facilitates the derivation of sector and organisation goals, objectives, outputs, activities, and input costs (World Bank, 1999).

With regards to the GDoH, it was clear that the recurrent and development expenditures are now integrated, and estimates are prepared for the budget year plus the two outer-years of the MTEF. At the centre, the aforementioned approach involved is the development of a macro- 
economic framework, the derivation of aggregate and sector expenditure ceilings, and the reprioritization of expenditure through the interaction of top-down ceilings and bottom-up estimates of expenditure, which is linked to objectives.

\section{The Impact of the Conditional Grant allocations}

It became evident that the conditional grant allocations to the Gauteng Department of Health was large, since the GDoH received, and is set continue to receive the majority share of all the conditional grants allocated to the Gauteng Provincial Government. The extent of conditional grant funding compared to other provincial departments may be interpreted differently. The National Treasury suggested that once nationally raised revenue has been divided amongst the spheres of government, the national government allocates further grants to Gauteng. These grants are made with different conditions, which the Gauteng Department of Health like any other receiving department, is expected to adhere to or to implement according to the conditions attached to such funding.

The GDoH participants also revealed that all if not most, of the national policies that are funded through conditional grants are adequately funded. The conditions that are attached to conditional grants mainly include monitoring provisions, specifications relating to the purpose for which the grants are to be used, timeframes and clearly defined outputs. An important factor that emerged from this research was that conditional grants are voted on the budgets of national departments but are spent at the provincial level. This has an important bearing on intergovernmental fiscal relations.

According to the Acting CFO of the Gauteng Department of Health, conditional grant transfers to the Gauteng Department of Health often imposed administrative costs on the department. However, Dr Mark Blecher argued that the issuance of conditional grants during the 2009 medium-term ensured that resources and priorities are protected, and stressed that these grants did not necessarily undermine the discretion of the Gauteng Provincial Legislature, but simply ensured that national policy priorities were implemented and that services were delivered to the people. The aforementioned views are supported by Donald Onyango, Director: Public Finance in the Social Sector at the Gauteng Provincial Treasury, who indicated that given the cash flow problems experienced by the Gauteng Department of Health, if all grants were to be transferred as equitable share, these funds would most likely be partially spent on addressing other critical problems facing the department, therefore, allocating funds in the form of conditional grants assisted in serving as protective mechanisms in the interest of service delivery.

It was concluded that the practice by the national government to allocate funds with specific conditions attached did not have a negative impact on service nor did it undermine the prerogative of the Gauteng Provincial Legislature to decide on where funds should be allocated.

\section{Competencies of the Planning and Budgeting Staff}

During engagements particularly with the senior officials from both the GDoH and the GPT, it became evident that the process of creating the department's budget did not involve specialists with health economics knowledge. It was admitted by both the GPT and the Gauteng Department of Health participants that the GDoH's current officials who are involved in the budgeting process are mainly from the fields of Accounting, Human resources, and traditional financial management. This admission was not to undermine the budgeting process, but to stress the important role that health economics could play in ensuring that health dynamics are taken into account from an economics perspective during the budgeting process. It was 
agreed that any discussion around the level of funding for health services cannot be comprehensive if it took place in the absence of critical skills that are necessary to make informed decisions.

The challenges facing the GDoH were also attributed generally to the lack of appropriately qualified and skilled human capacity within the overall provincial budgeting process to ensure that all relevant aspects of health financing are taken into account. The process also lacked the involvement of health clinicians to assist in the correct identification of key items and processes that are involved in the delivery of health services.

The funding mechanisms and processes followed were simply historical cost escalation by inflationary adjustments and incremental methods, where budget baselines were just increased without the basic information from the health institutions. The process was also weakened by the National Treasury that required the Gauteng Province to use uniform and rigid budget templates that did not require an input from clinicians who are based at hospital level.

\section{The Planning and Budgeting Process}

The Gauteng Department of Health participants had indicated that they are implementing the provincial budgeting process as issued by the Gauteng Provincial Treasury. The Gauteng Department of Health adopted the outcome-based budgeting to ensure the achievement of the set outcomes, which are with associated outputs, their related activities and inputs that were the basis for the crafting of the departments' estimates of revenue and expenditure, beginning from the year 2011. In all the key stages of the provincial budgeting process, the Gauteng Department of Health has been one of the participants and have planned and budgeted according to what the provincial budgeting process required. The issue at hand, while looking at the expenditure outcomes, according to the Acting CFO is the lack of content and credibility of the budgets submitted and finalised. The participant indicated that there is a strong prevalence of budget allocations that are not aligned to hospital plans and in other instances, budgets were allocated to wrong spending items. This was evident from the spending outcomes and the budget allocations made during the beginning of the financial year.

The GDoH was required to ensure that it also develops its own internal (hospital-based) budgeting process that is aligned with the provincial budgeting process. In the assessment of the degree of alignment between the public hospitals' processes against the provincial budgeting process, there were no clear indicators that demonstrated a significant degree of alignment. According to the Acting CFO, the Gauteng Department of Health had its own processes that were not fully aligned with the provincial budgeting process. It was mentioned that the GDoH waited for the provincial resource allocation process to be concluded by the Gauteng Provincial Treasury before they began engaging the different public health institutions. This exercise established that the Gauteng Department of Health, at Head Office level, had been for years planning and budgeting (top-down) for all their Gauteng public health institutions, with less involvement of the institutions themselves. The budget templates that were determined by the National Treasury as required by the Public Finance Management Act (PFMA), and used by the GDoH were only seen and used by the department at the Head Office and were not sent to public health institutions for them to do their planning and budgeting in line with such templates. This has consistently been one of the fundamental causes of the lack of credibility in the data that became final and published. 


\section{Challenges Affecting the Budgeting Process}

During the interview with the participant from Gauteng Provincial Treasury (GPT), the issue of leadership stability was mentioned as the major challenge that influenced the implementation of the provincial budgeting process. It was mentioned that leadership instability at the level of the Head of Department, has contributed to the imbalances in the manner in which the provincial budgeting process was implemented and, this had further negatively affected the level of funding the public health institutions in the Gauteng province.

It emerged that during the 2009-2014 political term the GDoH had appointed six Heads of Department, three in an acting capacity and the other three as substantial heads The Gauteng Department of Health. The Gauteng Provincial Treasury also indicated that this trend of leadership instability had contributed to the (poor) state of the GDoH, since every Head of Department had to learn the process, and each had their own way of thinking in terms of how public health institutions should be funded. The constant change in leadership caused interruptions on the provincial budgeting process and further led to imbalances in the level of funding of public hospitals, which eventually impacted on the level of service.

The degree to which the budget correlated with the actual service delivery at the public health institution level was said to be very poor because of the lack of clinical competency to inform the correct resource allocation. According to senior officials of the Gauteng Department of Health, the involvement of clinicians was required to make a meaningful input in terms of the kind of equipment, medicines, medical supplies, for example, which should be planned and budgeted for, mainly based on the utilisation rate at hospital and clinic level.

According to Onyango and Marokoane (2013), the GDoH has not brought all key internal stakeholders on board during the planning and budgeting process. It was argued that the budget of the entire department was developed at the Head Office and only by the finance unit due to a lack of sufficient time, and lack of interest in the financial aspects (budgets) by some health officials. This was clearly a case of disregarding the provisions of the Public Finance Management Act, which provides for the financial responsibilities of non-financial managers. The budgeting process excluded those critical officials like Head of District Hospital Support, Heads of Tertiary hospitals, Heads of conditional grant programmes, and many others. This has fundamentally led to budgets that were not aligned with the actual service delivery plans.

It was established that according to the provincial budgeting process, all Gauteng provincial government departments, including the Department of Health, have four months to develop plans and budgets for the MTEF. In this way the Gauteng Department of Health was required to make the necessary adjustments to cater for policy changes and developments within the macro-economic environment. The GDoH had not effectively implemented all the principles of the MTEF during its planning and budgeting processes, hence the annual imbalances in the spending outcomes.

A total of 200 outpatients were interviewed to basically determine their perceptions of public hospitals in Gauteng. Only 40 (20\%) respondents spread across all hospitals, race, age group and gender were satisfied with the quality of health services delivered by Gauteng public hospitals which they visited in the recent past, i.e. 1-2 years. Most of them sighted reasons ranging from negative attitude of hospital staff, lack of medicines and equipment, may be attributed mainly to lack of funding. 
The Gauteng Province is situated strategically and easily accessible from many areas in the country and from outside the country. In addition to people from other provinces and countries, the largest burden is the tendency of people to visit Gauteng's health facilities which offer a higher level of care than the primary health-care facilities in their localities. This had in the main, resulted in higher costs because of the equipment and health professionals in the tertiary facilities, while the same services could have been offered at lower costs by the Health Department if people have visited the primary health care facilities. In some instances, patients get referred to the provincial tertiary hospitals, but the referring institutions fail to honour (partially or in full) the related financial obligations.

The general public have a tendency of going straight to provincial and tertiary hospitals for primary health care that is offered freely or at low cost in the local clinics. For example, the Chris Hani Baragwanath Hospital is a tertiary hospital that offers high level of care and also serves as a health academic institution. The hospital has a catchment population of more than 3.64 million located in and around the Soweto Township. The hospital did not have a district or provincial hospital that is strategically located within the township to serve as a referral institution. This is one of the main causes of the high financial burden facing the hospital. Regardless of the level of its funding, the hospital will continue to face budget constraints due to offering highly specialised and expensive care which should have been offered by a district hospital.

The South African government's funding system of conditional grants generally contains three types of grants; supplementary, specific-purposes and in-kind allocations. With reference to the provincial sphere of government, these types of grants are separated and classified annually in terms of schedules of the Division of Revenue Act (DORA).

The lack of budgeting and planning competency became apparent, since budgets were developed using incremental methods based on past spending patterns and inflationary adjustments. The planning and budgeting staff in the department lacked statistical and econometric skills. The absence of district health information data to inform proper and informed service delivery planning and budgeting had an impact on the final spending outcomes. Furthermore, the lack of insight on the application of economic theory that underpins economic evaluation impacted on the budgets and service delivery.

\section{CONCLUSIONS AND RECOMMENDATIONS}

This research attempted to identify the factors that have an impact on the level of funding for the Gauteng public health service. The focus was mainly on the knowledge, views and convictions of various officials from relevant government departments who are part of the provincial budgeting process, in particular the National Department of Health, the Gauteng Provincial Treasury and the Gauteng Department of Health. Key role-players were identified and interviewed to establish if the Gauteng public health is adequately funded.

It became evident that public health is considered as a constitutional requirement, and a provincial priority. Although weaknesses were identified in the budgeting and health care planning processes, funding of health care in the province continues to receive high priority. The health portfolio receives a larger share of provincial budget, and is projected to receive increased funding in the near future. However, the Gauteng Department of Health has not fully developed its technical capacity in terms of the human resource requisite skills to be able to do proper planning and budgeting for health services. 
It became apparent that the provincial budgeting process did not include all key stakeholders, more especially clinicians at hospital level and health economists who are considered important. This has further undermined the importance of district health information that should be the basis for planning and budgeting for public hospitals. It is evident that the public health care funding system is flexible, in line with the South African intergovernmental fiscal relations, and provides for conditional grants from national to provinces for specific purposes. However, the onus is on the Department of Health to ensure that internal systems and processes (including capacity) are built, to enable the sustainability of health-care services even in the absence of conditional grant allocations to the province.

There was lack of effective communication of available resources and the policies to all the department's programme managers. This added to the leadership instability that also affected the assurance that funds are allocated appropriately. New leadership tended to cause erratic budget changes whenever a new Head of Department was appointed.

It was evident that budgeting was a top down process. In general, public hospitals and directorates receive their budgets which are merely an incremental increase over the past financial year's allocations, and to a large extent these 'increased' budgets were not aligned to operational plans. Budget allocations to the public hospitals were compiled late and did not adequately address the requests made at the budget committee meetings. Furthermore, it seemed that operational plans were not updated to reflect realistic activities and targets once the final budget allocation was made. Budget shifting took place between some programmes whereby under-utilised funds were transferred to areas where budgets were overspent. This practice negatively impacts on general financial management principles. There was also a lack of clear alignment between the annual performance plans and the relative financial budgets. The annual performance plans were also not updated subsequent to the allocation of funding.

The process of allocating budgets to the provincial Gauteng Department of Health is complex in that it involves funding from different sources. The Gauteng Department of Health should therefore look at implementing improvement strategies and ensure that planning and budgeting processes involve all the relevant stakeholders, inter-alia, hospital heads and all programme heads in the department. The department should gather and utilise district health data in planning and budgeting, and resource allocation should be based on data that is at clinic and hospital levels, as a bottom-up budgeting approach instead of developing the budget at Health Office level. The Gauteng Department of Health should review internal planning and budgeting process in the context of addressing inefficiencies and not anticipating additional funds to be allocated, since the problem may not be a lack of funds but the manner in which such available are allocated and utilised. The Gauteng Department of Health also needs to have more stringent internal controls to eliminate incidences of theft of state-owned assets.

\section{References}

Gauteng Department of Health. 2011. Gauteng Health Turnaround Strategy: "Towards effective service delivery, strengthening primary health care and a clean audit in 2014". Johannesburg: Gauteng Department of Health.

Gauteng Office of the Premier. 2013. Address by Gauteng Premier Nomvula Mokonyane on the occasion of the opening of the Gauteng Legislature. South African Government Information.

Gauteng Provincial Treasury. 2010. 2011 MTEF Treasury Guidelines. Johannesburg: Gauteng Provincial treasury.

Gauteng Provincial Treasury. 2013. Estimates of Provincial Revenue and Expenditure. Johannesburg: Gauteng Provincial Treasury. 
Rasivhetshele, R. E. \& Govender, K. K. (2014). Public health funding and health service delivery: A case study of the Gauteng province, South Africa. Archives of Business Research, 2(3), 50-61.

McIntyre, D. 2007. Equity in public sector health care financing and expenditure in South Africa. Public Sector Financing, pp. 29-43.

National Department of Health. 2007. National Health Insurance in South Africa: Policy Paper. Pretoria: National Department of Health.

National Department of Health. 2012. 2013 MTEF Annual Performance Plan. Pretoria: National Department of Health.

Onyango, D. 2013. Improving level of funding the Gauteng public healthcare system [interview] (Personal communication, 11 May 2013).

Public Finance Management Act No. 1 of 1999, as amended by Public Finance Management Act No. 29 of 1999. Pretoria: Government Printers.

Section 27. 2013. Monitoring Our Health: An analysis of the breakdown of health care services in selected Gauteng facilities. Johannesburg: Section 27.

Statistics South Africa. 2012. Census 2011. Pretoria: Statistics South Africa.

Stephen, S., Muirhead, D., Doherty, J. \& Muheki, C., 2000. Public Sector Financing. South African Health Review.

Thomas, S. \& Gibson, L. 2004. Actor dynamics in financing reform: The contested process of health insurance policy development in South Africa, 1994-1999. Cape Town: Health Economics Unit.

World Bank. 1999. Poverty Reduction and Economic Management. Washington: Malcolm Holmes.

World Health Organisation. 2010. World Health Report. Geneva: World Health Organisation.

Appendix A: Questionnaire

\begin{tabular}{|c|c|}
\hline $\begin{array}{l}\text { Question } \\
\text { No. }\end{array}$ & \\
\hline 1. & Do you think in Gauteng health service delivery is still a priority? \\
\hline 2. & $\begin{array}{l}\text { Who do you suggest or think should be primarily responsible to decide on resource allocation } \\
\text { between the national and provincial treasuries? }\end{array}$ \\
\hline 3. & Is the current provincial resource allocation process effective and where do you think gaps exist? \\
\hline 4. & $\begin{array}{l}\text { What is your view on the extent to which the current MTEF strives to achieve adequacy in public } \\
\text { health sector funding? }\end{array}$ \\
\hline 5. & $\begin{array}{l}\text { The MTEF seems to be working for provincial planning and budgeting, what is your view on the } \\
\text { effectiveness of the MTEF for the health sector financing? }\end{array}$ \\
\hline 6. & $\begin{array}{l}\text { What in your view and experience are the key factors that should be the basis for health sector } \\
\text { funding? What do you suggest as the most key cost-drivers that informs health expenditure? }\end{array}$ \\
\hline 7. & $\begin{array}{l}\text { In your view, would you agree that giving Gauteng Health more money will solve the current state of } \\
\text { service delivery? }\end{array}$ \\
\hline 8. & $\begin{array}{l}\text { If solutions are found to the problems facing the Gauteng Health, how long do you think it will take } \\
\text { to restore standard service delivery? }\end{array}$ \\
\hline 9. & Do you think that Health should be given funding preference form the provincial revenues? \\
\hline 10. & $\begin{array}{l}\text { If Health is funded equitably, what are the causes of the current problems that are being experienced } \\
\text { in the public health institutions? }\end{array}$ \\
\hline 12. & $\begin{array}{l}\text { What are your views with regards to the provincial process in terms of funding the Health sector in } \\
\text { Gauteng? }\end{array}$ \\
\hline 13. & $\begin{array}{l}\text { What is your view about the impact of conditionally allocating funds to the province, in relation to } \\
\text { the legislative authority of the Provincial Legislature? }\end{array}$ \\
\hline 14. & $\begin{array}{l}\text { If the provincial allocation process had full authority to allocate, do you think this would have } \\
\text { promoted equity in allocating to the public Health in Gauteng? }\end{array}$ \\
\hline 15 . & $\begin{array}{l}\text { The imbalances in spending outcomes, may it have anything to do with spending decision by Health } \\
\text { or are it due the imbalances in the provincial allocation process? }\end{array}$ \\
\hline 16. & $\begin{array}{l}\text { What will be your final recommendations in terms of how adequacy should be achieved in health } \\
\text { sector funding? }\end{array}$ \\
\hline
\end{tabular}


Respondents were asked to indicate their extent of agreeing or disagreeing with each statement by marking the appropriate number using the six point scale provided for each question, where:

1. Strongly disagree

2. Disagree

3. Partially disagree

4. Partially agree

5. Agree

6. Strongly agree

\begin{tabular}{|c|c|c|c|c|c|c|c|}
\hline \multirow[t]{2}{*}{ No. } & \multirow[t]{2}{*}{ Actual Question (Questionnaire) } & \multicolumn{6}{|c|}{$\begin{array}{l}\text { Ranking of } \\
\text { responses }\end{array}$} \\
\hline & & 1 & 2 & 3 & 4 & 5 & 6 \\
\hline 1. & $\begin{array}{l}\text { Does your current role have responsibilities to ensure the adequacy of funding of the } \\
\text { Gauteng public health? }\end{array}$ & & & & & & \\
\hline 2. & Would you agree/disagree that the MTEF has worked for other public sectors than health? & & & & & & \\
\hline 3. & $\begin{array}{l}\text { Would you say the MTEF process addresses the principle of adequacy in Gauteng health } \\
\text { funding? }\end{array}$ & & & & & & \\
\hline 4. & Would you suggest that the MTEF be reviewed as a tool used in funding health sector? & & & & & & \\
\hline 5. & Does the current provincial resource allocation process takes public health as a priority? & & & & & & \\
\hline 6. & $\begin{array}{l}\text { Would you think that the provincial resource allocation process is addressing efficiency in } \\
\text { Gauteng health sector funding? }\end{array}$ & & & & & & \\
\hline 7. & $\begin{array}{l}\text { The current state of public health sector in Gauteng is as is because of inadequate or } \\
\text { inappropriate financing methods. }\end{array}$ & & & & & & \\
\hline 8 & $\begin{array}{l}\text { The provincial resource allocation process is more biased towards the public health } \\
\text { sector. }\end{array}$ & & & & & & \\
\hline 9. & $\begin{array}{l}\text { Would you suggest that the provincial resource allocation process be reviewed as a tool } \\
\text { used in funding health sector? }\end{array}$ & & & & & & \\
\hline 10. & $\begin{array}{l}\text { Would you suggest the adoption of new allocation processes especially for the health } \\
\text { sector? }\end{array}$ & & & & & & \\
\hline 11. & $\begin{array}{l}\text { If the status quo is kept, would you suggest that the health problems in Gauteng will only } \\
\text { get worse? }\end{array}$ & & & & & & \\
\hline
\end{tabular}

Questionnaire for Outpatients

\begin{tabular}{|l|l|l|}
\hline $\begin{array}{l}\text { Hospital } \\
\text { Name }\end{array}$ & & Answers \\
\hline Race & & \\
\hline Age & & \\
\hline Gender & Are you satisfied with the service you get in public hospitals? & \\
\hline Q1 & $\begin{array}{l}\text { How do you find the hospital staff attitude and services they offer to } \\
\text { patients? }\end{array}$ & \\
\hline Q3 & $\begin{array}{l}\text { Do you think hospitals have enough machinery and equipment to offer } \\
\text { good services? }\end{array}$ & \\
\hline Q4 & $\begin{array}{l}\text { Where do you think problems are in public hospitals? } \\
\text { Q5 }\end{array}$ & $\begin{array}{l}\text { In your opinion, do you think Gauteng government hospitals are } \\
\text { properly funded? }\end{array}$ \\
\hline
\end{tabular}

